\title{
CANVAS an update: Clinical presentation, investigation and management
}

\author{
David J. Szmulewicz ${ }^{\mathrm{a}, *}$, Catriona A. McLean ${ }^{\mathrm{b}}$, Hamish G. MacDougall ${ }^{\mathrm{c}}$, Leslie Roberts ${ }^{\mathrm{d}}$, \\ Elsdon Storey ${ }^{\mathrm{e}}$ and G. Michael Halmagyi ${ }^{\mathrm{f}}$ \\ ${ }^{a}$ Royal Victorian Eye \& Ear Hospital, University of Melbourne, Melbourne, Australia \\ ${ }^{\mathrm{b}}$ Department of Anatomical Pathology, Alfred Hospital, Melbourne, Australia \\ ${ }^{\mathrm{c}}$ Vestibular Research Laboratory, School of Psychology, University of Sydney, Sydney, Australia \\ ${ }^{\mathrm{d}}$ Department of Neuroscience, St Vincent's Hospital, Melbourne, Australia \\ ${ }^{\mathrm{e}}$ Department of Neuroscience, Monash University, Melbourne, Australia \\ ${ }^{\mathrm{f}}$ Department of Neurology, Royal Prince Alfred Hospital, Sydney, Australia
}

Received 14 May 2014

Accepted 14 August 2014

\begin{abstract}
.
BACKGROUND: Cerebellar Ataxia with Neuropathy and bilateral Vestibular Areflexia Syndrome (CANVAS) is a multi-system ataxia which results in cerebellar ataxia, a bilateral vestibulopathy and a somatosensory deficit. This sensory deficit has recently been shown to be a neuronopathy, with marked dorsal root ganglia neuronal loss. The characteristic oculomotor clinical sign is an abnormal visually enhanced vestibulo-ocular reflex.

OBJECTIVE: To outline the expanding understanding of the pathology in this condition, as well as diagnostic and management issues encountered in clinical practice.

METHODS: Retrospective data on 80 CANVAS patients is reviewed.

RESULTS: In addition to the triad of cerebellar impairment, bilateral vestibulopathy and a somatosensory deficit, CANVAS patients may also present with orthostatic hypotension, a chronic cough and neuropathic pain. Management of falls risk and dysphagia is a major clinical priority.

CONCLUSIONS: CANVAS is an increasingly recognised cause of late-onset ataxia and disequilibrium, and is likely to be a recessive disorder.
\end{abstract}

Keywords: Cerebellar ataxia, vestibulopathy, neuronopathy, ganglionopathy

\section{Introduction}

Cerebellar Ataxia with Neuropathy and Vestibular Areflexia Syndrome (CANVAS) is a slowly progressive ataxic disorder characterised by the combination of bilateral vestibular, cerebellar and somatosen-

* Corresponding author: David Szmulewicz, Balance Disorders \& Ataxia Service, Royal Victorian Eye and Ear Hospital, 32 Gisborne Street, East Melbourne VIC, 3002, Australia. Tel.: +613 9929 8666; Fax: +613 9012 4465; E-mail: dsz@me.com. sory impairment [44]. An abnormal visually enhanced vestibulo-ocular reflex (VVOR) reflects a compound deficit of the three compensatory oculomotor reflexes: the vestibulo-ocular reflex (VOR), the optokinetic reflex, and smooth pursuit [30]. Hence, an abnormal VVOR (see Fig. 1) is seen in patients with CANVAS $[32,44]$ reflecting cerebellar and bilateral vestibular dysfunction (see Figs 2-4) [1,4,30,38,44,45,49]. An impaired VVOR can be demonstrated clinically by turning a patient's head slowly (at approximately $0.5 \mathrm{~Hz}$ ) while the patient visually fixates upon an 


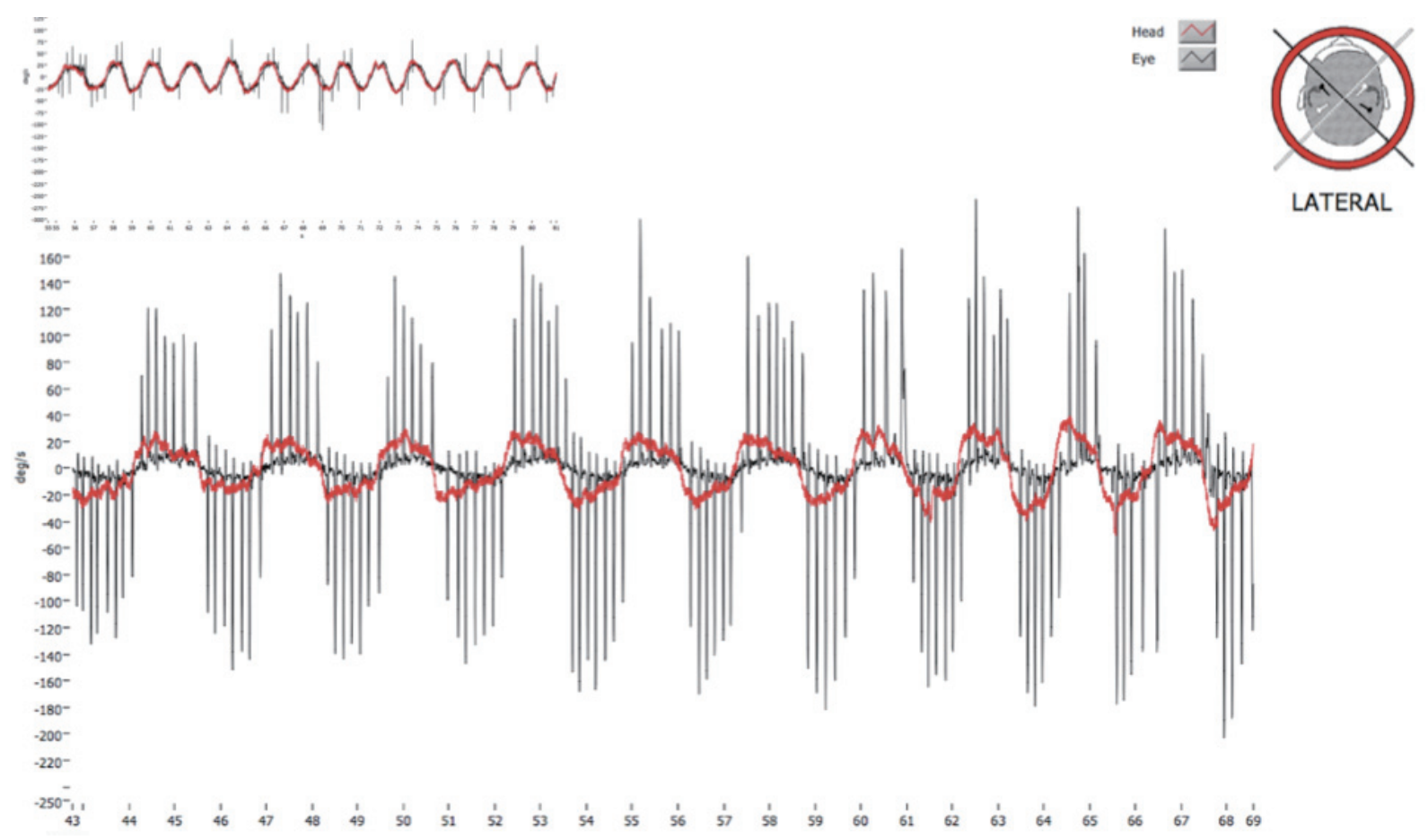

Fig. 1. Abnormal horizontal visually-enhanced vestibulo-ocular reflex (VVOR) in a patient with CANVAS. Head rotation stimulus is shown in red; eye movement response is shown in black. Inset: normal horizontal VVOR gain $(\sim 1)$, recorded using portable rapid video-oculography equipment. Main panel: diminished VVOR gain followed by salvos of compensatory saccades. (Colours are visible in the online version of the article; http://dx.doi.org/10.3233/VES-140536)

earth-fixed target and observing that the compensatory eye movements are saccadic rather than smooth (see Fig. 1). Hearing is unaffected. We have seen 80 patients, including thirteen kindreds with this not uncommon condition [42] (from a population of approximately 10 million people). Our understanding of this disorder has deepened as we uncover the clinical [44], pathological [43-45] radiological [45], neurophysiological and genetic [46] details of this condition.

The timing of the onset of the various components of CANVAS may vary. Where the patient presents with the triad of: bilateral vestibulopathy, cerebellar dysfunction and a somatic sensory deficit (having ruled out other possible causes including spinocerebellar ataxia type $3[5,6,12,20,40,47]$ and Friedreich's ataxia $[8,11,21,35]$ the diagnosis may be relatively straightforward. However, in those patients where a significant delay in the manifestation of all three cardinal features exists, diagnosis may be more challenging (see Table 1). In our experience the onset of the final component of the diagnostic triad may take more than 10 years, such that a patient with cerebellar ataxia and bilateral vestibulopathy (CABV) (or any other combination of two of the three cardinal features of CAN-
VAS) should have baseline investigations, and then be reviewed at regular intervals to ascertain whether they had indeed initially presented with CANVAS in evolution.

Amongst our CANVAS patients, there are three to date with no clinical signs of a peripheral sensory deficit (for example, diminished sensory perception and abnormal deep tendon reflexes), who yet have decreased or absent sensory nerve action potentials (SNAPs) on neurophysiological testing. For this reason, and to document baseline testing in those who may have CANVAS in evolution, we routinely perform nerve conduction studies on all patients with CABV.

We have previously delineated a differential pattern of cerebellar atrophy that preferentially affects the anterior and dorsal vermis (lobules VI, VIIa, and VIIb) and laterally, predominantly affecting crus I [44] (see Fig. 5). Additionally, a multiple cranial nerve neuronopathy (ganglionopathy) affecting cranial nerves $\mathrm{V}$, VII and the vestibular portion of VIII has been demonstrated $[43,46]$. Selective atrophy of the vestibular nerves and marked diminution of the number of Scarpa's ganglion cells with atrophic peripheral and central axons is seen, whilst the auditory nerve and 

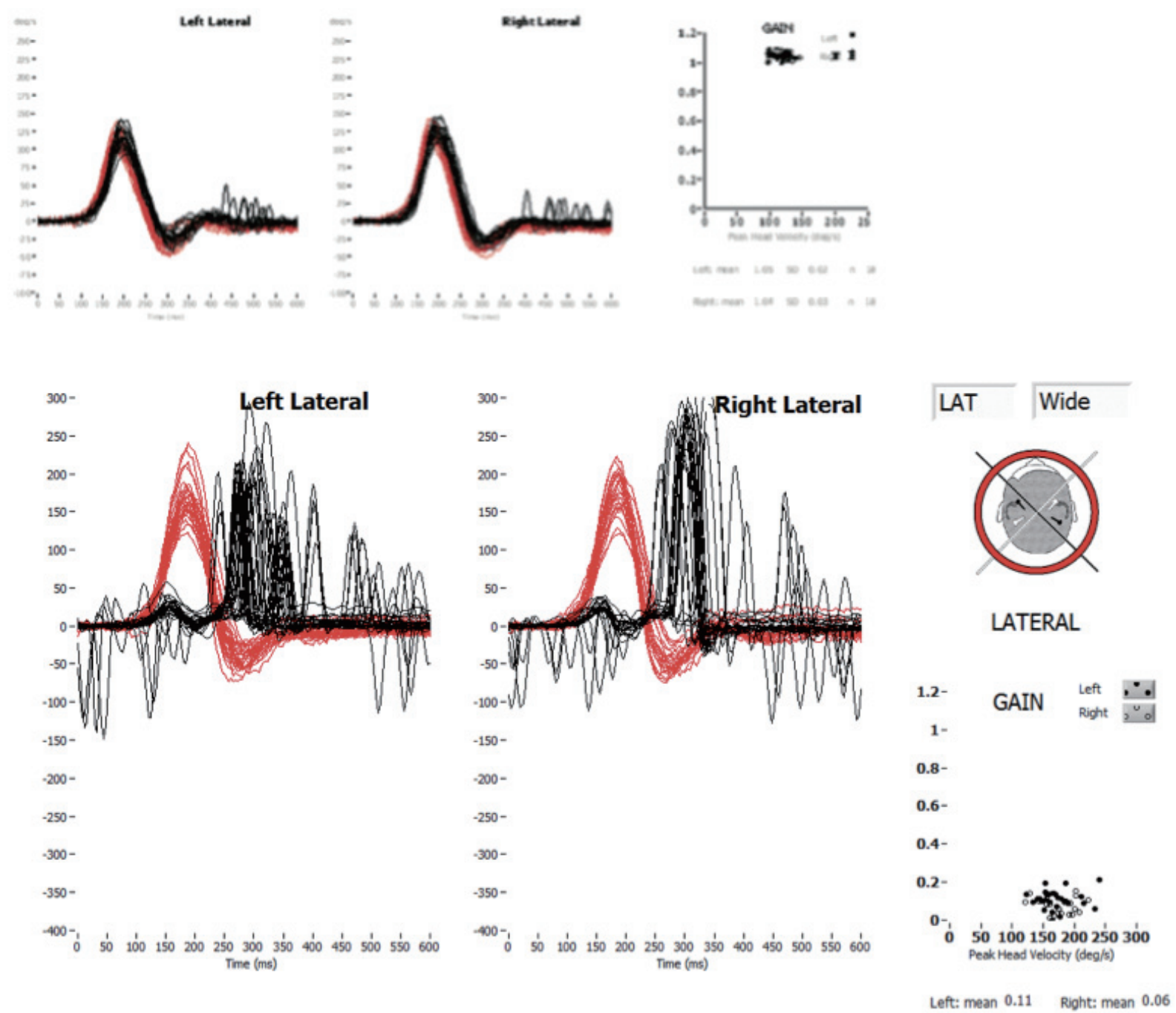

Fig. 2. Bilateral vestibulopathy demonstrated on video head impulse testing of a patient with CANVAS. Head rotation stimulus is shown in red; eye movement response is shown in black. Inset: normal bilateral horizontal VOR gain $(\sim 1)$. Main panel: profound bilateral VOR gain deficit (peak VOR gain $<0.2$ ), followed by compensatory saccades. (Colours are visible in the online version of the article; http://dx.doi. org/10.3233/VES-140536)

end-organ are unaffected (Fig. 6). The cristae and maculae show a normal population of hair cells and supporting cells [43]. We have now uncovered the third focus of pathology: marked atrophy of the dorsal root ganglia with resultant posterior column atrophy [46]. Sub-total neuronal loss in the dorsal root ganglia is seen. Consequentially, posterior columns show severe loss of myelinated axons with normal anterior and lateral horns. Similarly, secondary peripheral neuronal degeneration is seen in the sural nerve (Fig. 7). Hence, the somatic sensory deficit seen in CANVAS is a 'neuronopathy' rather than a 'neuropathy', as we previously believed [44] (see Table 1 for details of the clinical somatosensory deficit) and this presents another target of diagnostic investigation in the clinical assessment of the ataxic patient.

Amongst our patients we have 13 kindreds, which vary from sibling pairs to multiple affected family members over greater than one generation. Our efforts at identification of the culprit genetic mutation are progressing, and at present it appears that inheritance is most likely to conform to an autosomal recessive model, although an autosomal dominant pattern with markedly decreased penetrance is possible. Of course, the possibility of phenocopies cannot be excluded until the culprit gene is isolated and routine testing is applied. Additionally, the variability in presentation (for example the predominance of vestibular over cerebel- 


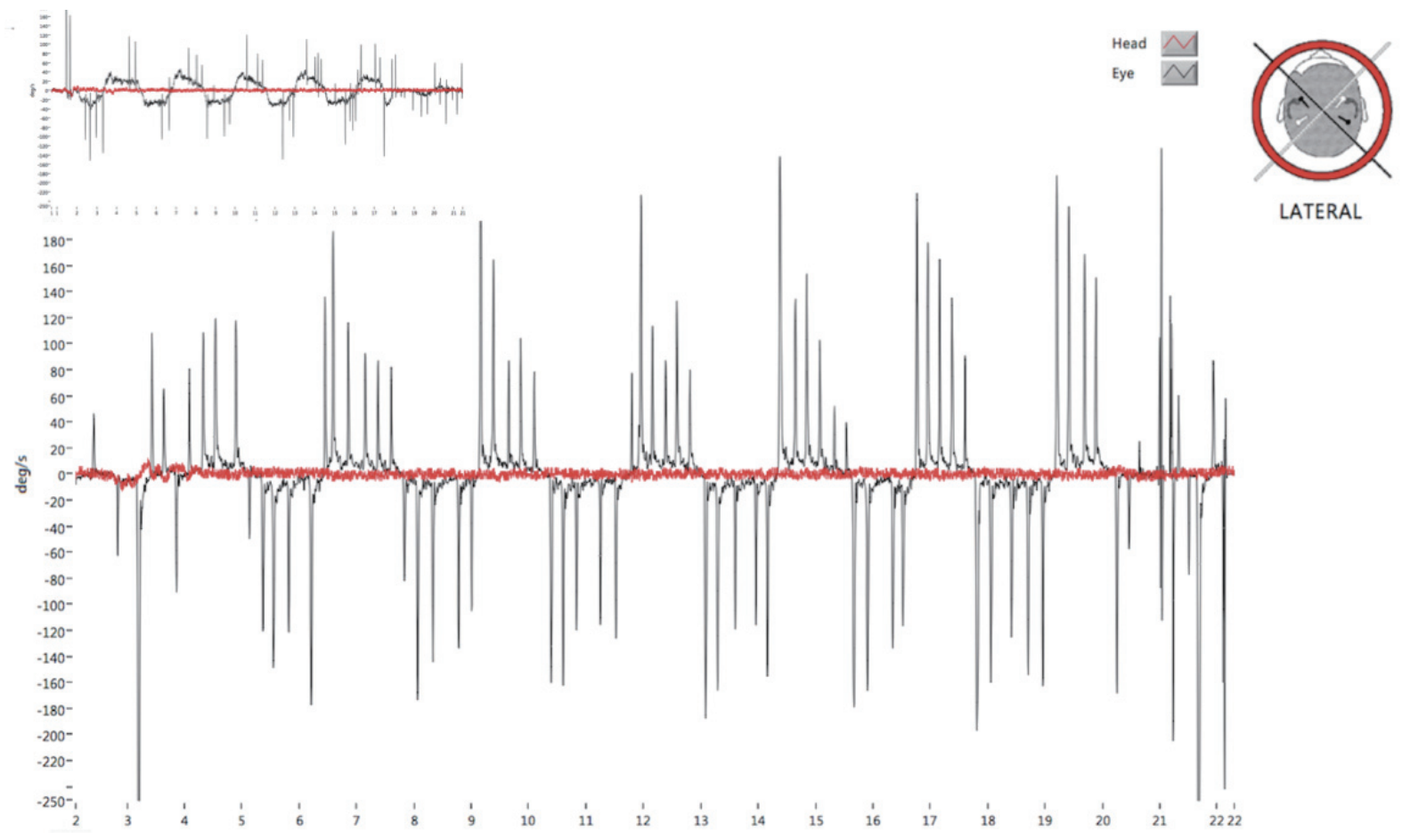

Fig. 3. Saccadic smooth pursuit in a CANVAS patient. Inset: head is stationary (red trace), whilst patient is visually tracking a horizontally moving target $(0.66 \mathrm{HZ})$ and eye movement is shown in black. Main panel: note the numerous, high amplitude corrective saccades that result in 'broken-up' smooth pursuit. (Colours are visible in the online version of the article; http://dx.doi.org/10.3233/VES-140536)

lar impairment or the presence of small $(\mathrm{A} \delta)$ fibre peripheral nerve involvement in some) particularly between families, may be due to heterogeneity (phenotypic, genotypic or allelic).

We screen all potential CANVAS patients for spinocerebellar ataxia (SCA) type 1, 2, 3, 6 and 7 as there is considerable variability in their presentation [39] and these genetic tests are generally available. Of these, it is particularly SCA3, which may result in cerebellar ataxia, a bilateral peripheral vestibulopathy $[5,6,12,47]$ and a sensory neuropathy $[20,40]$. Adult onset Friedreich's ataxia may also result in the combination of cerebellar impairment [21] a bilateral vestibulopathy [8,11] and a sensory neuronopathy [22,35], and so we also perform a Friedreich's ataxia gene test gene prior to diagnosing CANVAS.

We have found chronic cough and autonomic dysfunction to be variable features of CANVAS. Many patients report a relatively long-standing chronic, nonproductive cough that may have preceded the onset of imbalance and somatosensory impairment. The cause of this cough is yet to be elucidated but may be the sequela of a vagal neuronopathy and denervation hypersensitivity of the upper airways and oesophagus [41]. Clinical features referable to autonomic dysfunction may be seen in CANVAS patients, and most commonly includes hypohidrosis and orthostatic hypotension. Orthostatic hypotension is a sustained reduction of systolic blood pressure of at least $20 \mathrm{mmHg}$ (or diastolic blood pressure of $10 \mathrm{mmHg}$ ) within 3 minutes of standing (or head-up tilt to at least 60 degrees on a tilt table) [10]. Small (A $\delta$ ) fibre sensory nerve involvement may be demonstrated neurophysiologically, but where limited specialty investigation is available, we find that the combination of examination of the patient's socks for the absence of moisture and accurately performed lying and standing blood pressure measurements to be acceptable indicators of autonomic dysfunction, which may reflect possible small fibre pathology. Management of postural hypotension is of the utmost importance as part of a comprehensive approach to falls prevention. Whilst imbalance is not a useful clinical clue to the presence of orthostatic hypotension in a patient with CANVAS, we have found that specific questioning about light headedness on sitting up from lying or standing from sitting, to be relatively reliable indicators for the need to perform formal autonomic investigations. We have generally found that the combination of avoiding drug-induced orthostatic hypotension (see Table 2) and adequate hydration (particularly 
Table 1

Clinical evaluation of the potential CANVAS patient

\begin{tabular}{|c|c|c|c|}
\hline $\begin{array}{l}\text { Component of the } \\
\text { CANVAS triad }\end{array}$ & Abnormality & Clinical examination finding & $\begin{array}{l}\text { Suggested/Preferred investigative } \\
\text { modalities }\end{array}$ \\
\hline $\begin{array}{l}\text { Bilateral } \\
\text { vestibulopathy }\end{array}$ & $\begin{array}{l}\text { Decreased VOR gain bilaterally } \\
\text { Abnormal VVOR }\end{array}$ & $\begin{array}{l}\text { Bi-directionally abnormal horizontal } \\
\text { head impulse test. } \\
\text { Saccadic bedside VVOR }\end{array}$ & $\begin{array}{l}\text { Rapid video-oculography }{ }^{3} \\
\text { (see Fig. 2), video nystagmography or } \\
\text { rotational chair testing }\end{array}$ \\
\hline \multirow[t]{5}{*}{$\begin{array}{l}\text { Cerebellar } \\
\text { impairment }\end{array}$} & Cerebellar atrophy & N/A & $\begin{array}{l}\text { MRI evidence of anterior and dorsal } \\
\text { vermal atrophy, and laterally, hemi- } \\
\text { spheric atrophy predominantly affect- } \\
\text { ing crus I (see Fig. 6) }\end{array}$ \\
\hline & Cerebellar dysarthria & Dysarthric speech & $\begin{array}{l}\text { Formal speech therapy (speech } \\
\text { pathology) assessment, including } \\
\text { swallow assessment where clinically } \\
\text { indicated }\end{array}$ \\
\hline & Appendicular ataxia & $\begin{array}{l}\text { For example, evidence of upper } \\
\text { and lower limb dysmetria, intention } \\
\text { tremor \& dyssynergia }\end{array}$ & N/A \\
\hline & Dysphagia of cerebellar origin & N/A & Video fluoroscopy \\
\hline & $\begin{array}{l}\text { Cerebellar oculomotor abnormali- } \\
\text { ties }\end{array}$ & $\begin{array}{l}\text { Impaired smooth pursuit and }{ }^{*} \text { VOR } \\
\text { suppression; gaze-evoked nystagmus; } \\
\text { dysmetric saccades to target; rebound } \\
\text { nystagmus, pure vertical or torsional } \\
\text { nystagmus }\end{array}$ & $\begin{array}{l}\text { Rapid video-oculography }{ }^{3} \text {, video } \\
\text { nystagmography, rotational chair } \\
\text { testing (see Figs } 3 \text { and } 4 \text { ) }\end{array}$ \\
\hline $\begin{array}{l}\text { Somatosensory } \\
\text { impairment }\end{array}$ & $\begin{array}{l}\text { Neurophysiological evidence of a } \\
\text { neuronopathy }\end{array}$ & $\begin{array}{l}\text { Sensory deficit in one or more of light } \\
\text { touch, pin prick, vibration or proprio- } \\
\text { ception. }\end{array}$ & $\begin{array}{l}\text { Neurophysiological studies demon- } \\
\text { strating reduced or absent SNAPs in a } \\
\text { pattern indicative of a neuropathy or } \\
\text { neuronopathy }\end{array}$ \\
\hline $\begin{array}{l}\text { Additional } \\
\text { requirement }\end{array}$ & $\begin{array}{l}\text { Exclusion of genetic ataxias able to } \\
\text { be gene tested, particularly SCA3 } \\
\text { and Friedreich's ataxia }\end{array}$ & & \\
\hline
\end{tabular}

*NB: where VOR gain is markedly reduced, VOR suppression may appear to be relatively normal as there is little VOR activity to suppress; N/A: not applicable.

Table 2

Select common causes of drug-induced orthostatic hypotension [49]

\begin{tabular}{ll}
\hline Pharmacological class & Drug examples \\
\hline Diuretics & frusemide, hydrochlorothiazide \\
Alpha adrenoreceptor antagonists & alfuzosin, tamsulosin \\
Beta adrenoreceptor antagonists & propranolol, labetalol \\
Antidepressant agents & imipramine, mianserin \\
Angiotensin-converting enzyme inhibitors (ACEI) & captopril, lisinopril \\
Phosphodiesterase type 5 (PDE5) inhibitor & sildenafil, tadalafil \\
Nitrates & glyceryl trinitrate (nitroglycerine), isosorbide dinitrate \\
\hline
\end{tabular}

important in warmer climates), wearing elastic stockings [28] and fludrocortisone at a dose of 0.1 to $0.2 \mathrm{mg} /$ day $[7,29]$ to be adequate management. Occasionally, the addition of the vasopressor midodrine is required at doses of 5-10 mg three times daily (as duration of action is short (2 to 4 hours)) [9,16,24]. Dosing should occur no later than 3 to 4 hours before bedtime because of the risk of supine hypertension. In order to minimise adverse medication effects, we recommend frequent monitoring of serum potassium, a diet high in potassium and regular measurement of supine blood pressure (especially where dual therapy is undertaken) [7, 29].
Particularly where a clinical suspicion of autonomic dysfunction exists, investigation for a possible small fibre neuropathy or neuronopathy may be indicated. We employ the combination of sudomotor or so called 'sweat tests' (we have used the QSART system), tilt table testing and measurement of the cutaneous silent period (CSP) in the upper and lower limbs [24]. The material risks to the longevity in CANVAS patients centre on the sequelae of aspiration and falls. For this reason we have a very low threshold for formal swallow assessment, which in our institutions involves referral to a speech therapist and video fluoroscopy. Although yet to be definitively elucidated, CANVAS pa- 


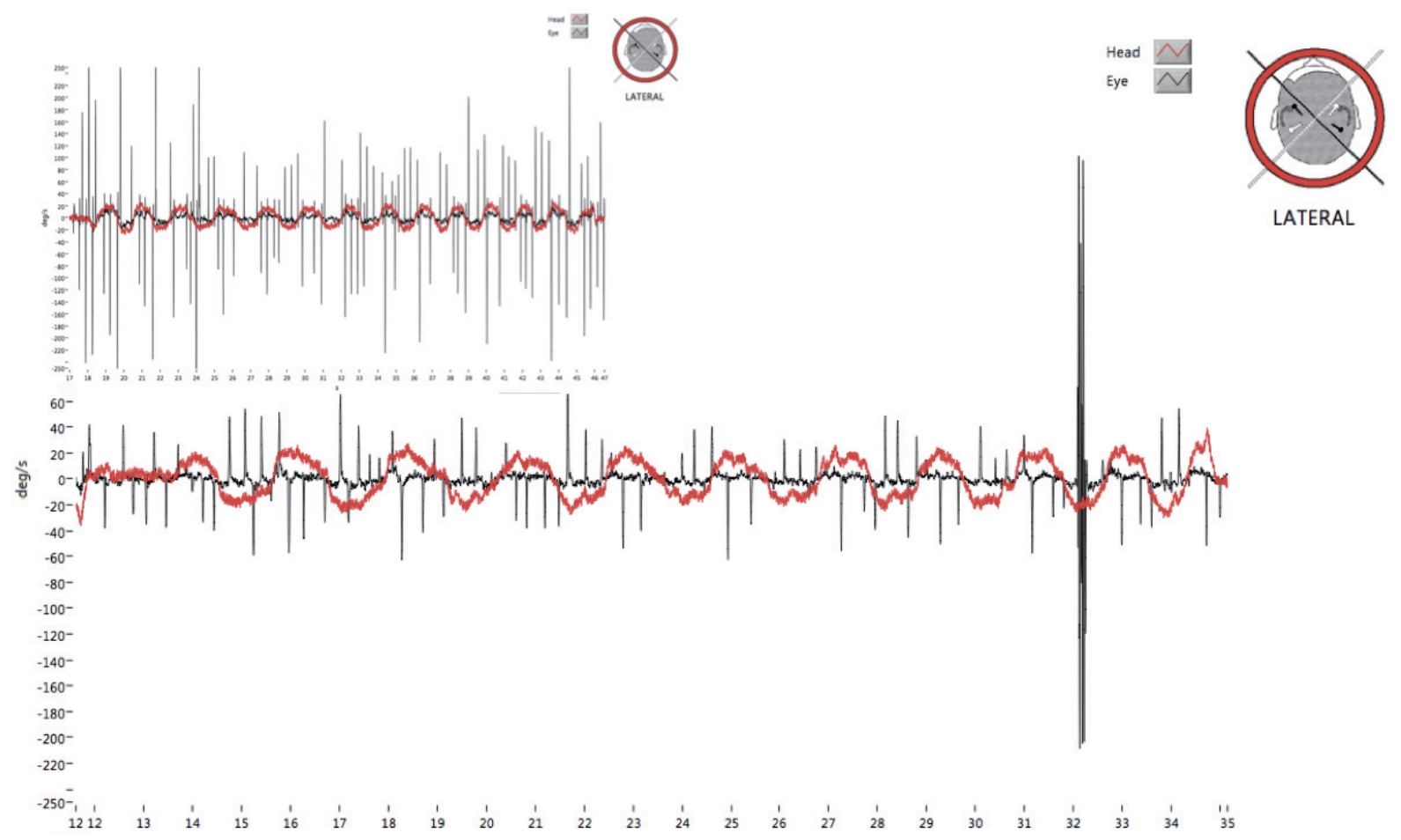

Fig. 4. Normal vestibulo-ocular reflex suppression (VORS). Head rotation stimulus is shown in red; eye movement response is shown in black. Inset: a patient with a pure cerebellar syndrome visually tracking a head fixed target during slow $(0.5 \mathrm{HZ})$ sinusoidal head movements in the yaw plane, many high amplitude corrective saccades are seen. Main panel: CANVAS patient, the VORS is paradoxically normal (only occasional, low amplitude saccades are seen) as there is minimal VOR gain to suppress. (Colours are visible in the online version of the article; http://dx. doi.org/10.3233/VES-140536)

tients may be dyspahagic as a result of pharyngeal incoordination (as seen in patients with pure cerebellar syndromes) and/or sensory impairment (for example reduced trigeminal, chorda tympani, glossopharyngeal and pharyngeal branch of the vagus nerve input). Our experience is that most CANVAS patients with dysphagia respond to so called indirect strategies - involving behavioural techniques such as the chin-tuck position (which decreases the space between the base of the tongue and the posterior pharyngeal wall) thus functioning to increase pharyngeal pressure on the food and hence, aid its passage through this region $[33,34]$. Very few of our patients have required modification of their food consistency (such as the addition of thickening agents).

\section{Falls and their sequelae}

In terms of loss in disability-adjusted years for people aged 50 years or older, hip fracture ranks in the top 10 causes [34]. Particularly with increasing age, the sequelae of hip fracture include very substantial impacts on mortality and morbidity. The 1 year mortality rate for a fractured neck of femur is between 20 and 35 per cent $[18,37,48]$. Potential sources of morbidity associated with hip fractures include deep vein thrombosis, post-operative infection and loss of mobility [3]. There is no published data on the incidence of falls in CANVAS patients, but our experience is that these patients are at an increased risk of multiple falls when compared to their unaffected peers. We routinely perform dual-energy X-ray absorptiometry (DEXA bone densitometry) scans for evidence of osteopenia or osteoporosis [2,27] (which are treated with bisphosphonates or strontium ranelate) and even in the absence of these diagnoses, advise ongoing treatment with calcium and vitamin D supplementation to reduce fracture risk [25]. For all but our most mildly affected patients we advise comprehensive assessment at a multi-disciplinary community falls and balance clinic, which includes a home-based occupational therapy assessment in order to identify potential falls risks in the patient's home, to advise on bathroom modifications, placement of grab rails, etcetera. 

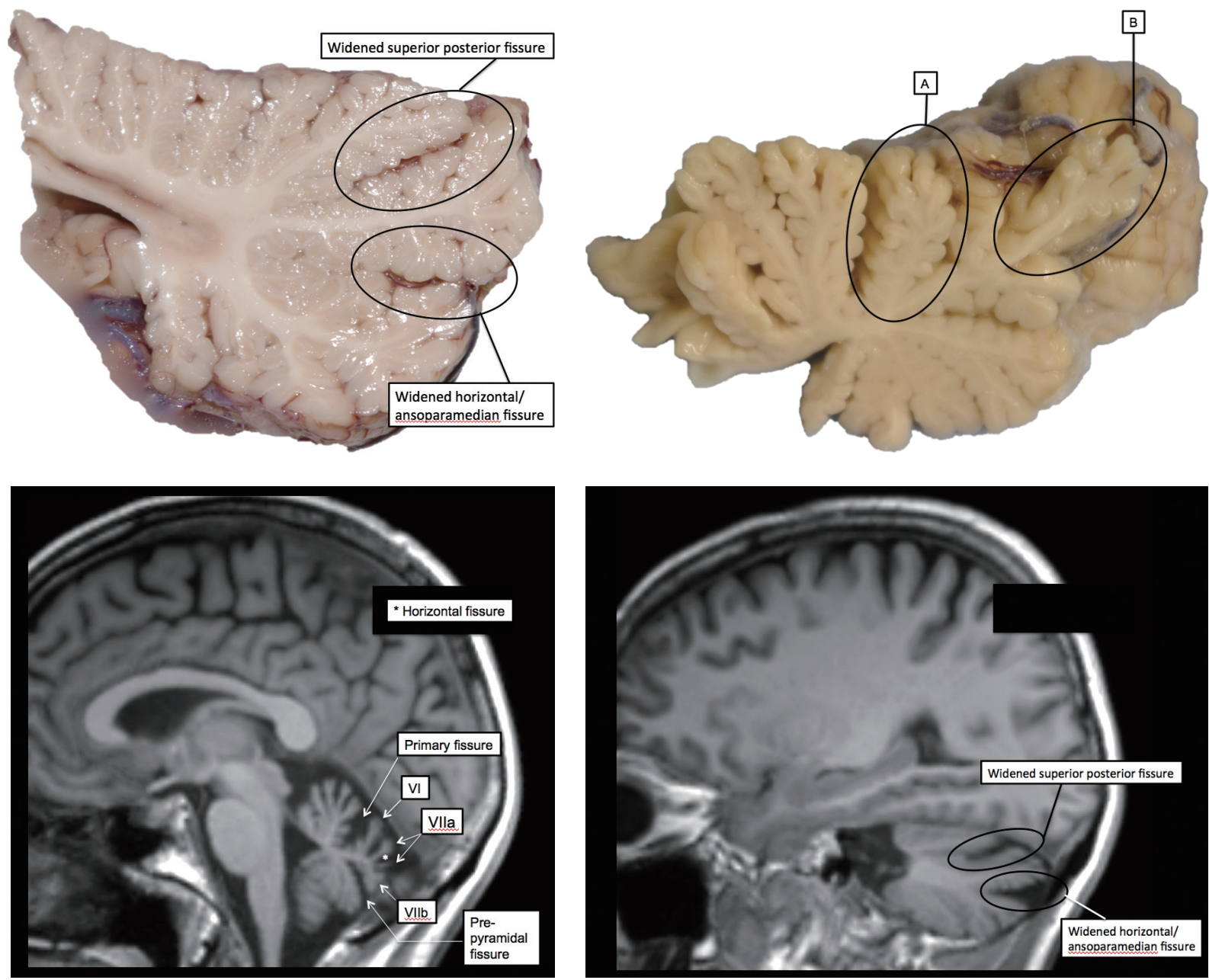

Fig. 5. Cerebellar atrophy in CANVAS. First panel: cerebellar atrophy is evident by widening of the superior posterior and horizontal fissures in a parasagittal macroscopic section; Second panel: anterior (A) and dorsal (B) cerebellar vermal atrophy (dorsal vermis corresponds to vermal lobules VI, VIIa and VIIb); Third panel: parasagittal view displaying widening of the superior posterior and horizontal fissures as a result of atrophy (T1-weighted MRI brain of a 46 year old CANVAS patient); Final panel: midsagittal view shows anterior and dorsal vermal atrophy (the latter relates to vermal lobules VI, VIIa and VIIb). (Colours are visible in the online version of the article; http://dx.doi.org/10.3233/VES-140536)

\section{Vestibular rehabilitation}

Whilst evidence exists for the utility of intensive neurological physiotherapy in the management of cerebellar disease $[14,15]$ and similarly vestibular rehabilitation in the treatment of bilateral peripheral vestibulopathies $[13,23,36]$, there does not appear to be any published data on the combination of these two therapies in the management of patients with compound deficits of cerebellar, vestibular and somatosensory impairment. Anecdotally, we find significant benefit in referring our patients for individualised combination neurological and vestibular rehabilitation, which are performed regularly by the patient and reviewed periodically by a specialist physiotherapist.

\section{Pain}

Neuropathic pain, dysaesthesia and allodynia may be particularly troubling for those patients with CANVAS. This most likely reflects a degree of small fibre involvement in their somatosensory impairment. We have found membrane stabilising agents to be singularly useful in controlling these symptoms. Pregabalin may be extremely effective and in our experience is generally well tolerated. We begin treatment with a dose of $75 \mathrm{mg}$ twice daily and up-titrate the dosage in $75 \mathrm{mg}$ aliquots, as required, to a maximum dose of $300 \mathrm{mg}$ daily. It may take several weeks to achieve maximal effect with pregabalin. Where a positive and sustained treatment response has occurred, 


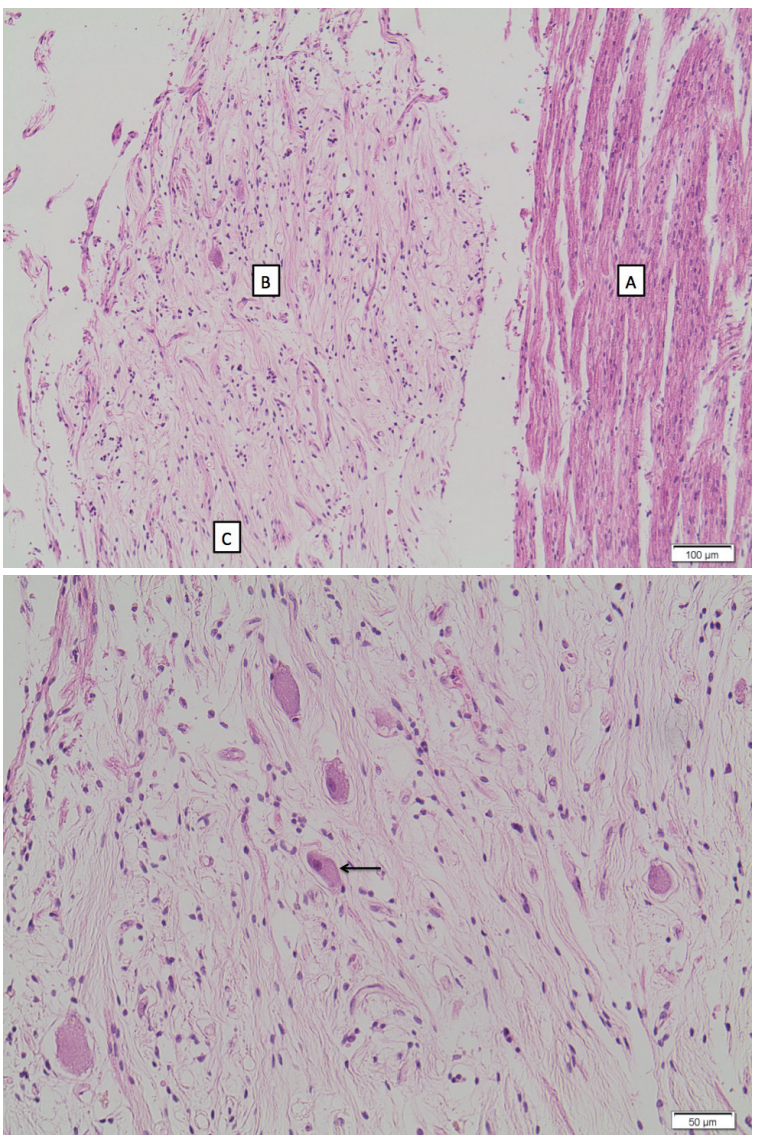

Fig. 6. Scarpa's (vestibular) ganglion. Top panel: normal myelinated auditory nerve (A) and atrophic Scarpa's (vestibular) ganglion (B) (atrophic vestibular nerve can be seen entering the ganglion in the lower portion of the image (C)); low power, haematoxylin and eosin (H\&E); Lower panel: atrophic Scarpa's ganglion with scant residual neurones (arrow); high power, H\&E. (Colours are visible in the online version of the article; http://dx.doi.org/10.3233/VES-140536)

consideration is given to gradually reducing the dose over time [32]. We have also used amitriptyline in this setting, but have found pregabalin to be more effective and better tolerated by our patients.

\section{Conclusion}

CANVAS is an increasingly recognised cause of late-onset ataxia and disequilibrium. It offers a fascinating physiological and pathological insight into the multi-system nature of human balance. Whilst cure is an omnipresent goal, management options exist and are increasing, as we learn more about this complex disorder.
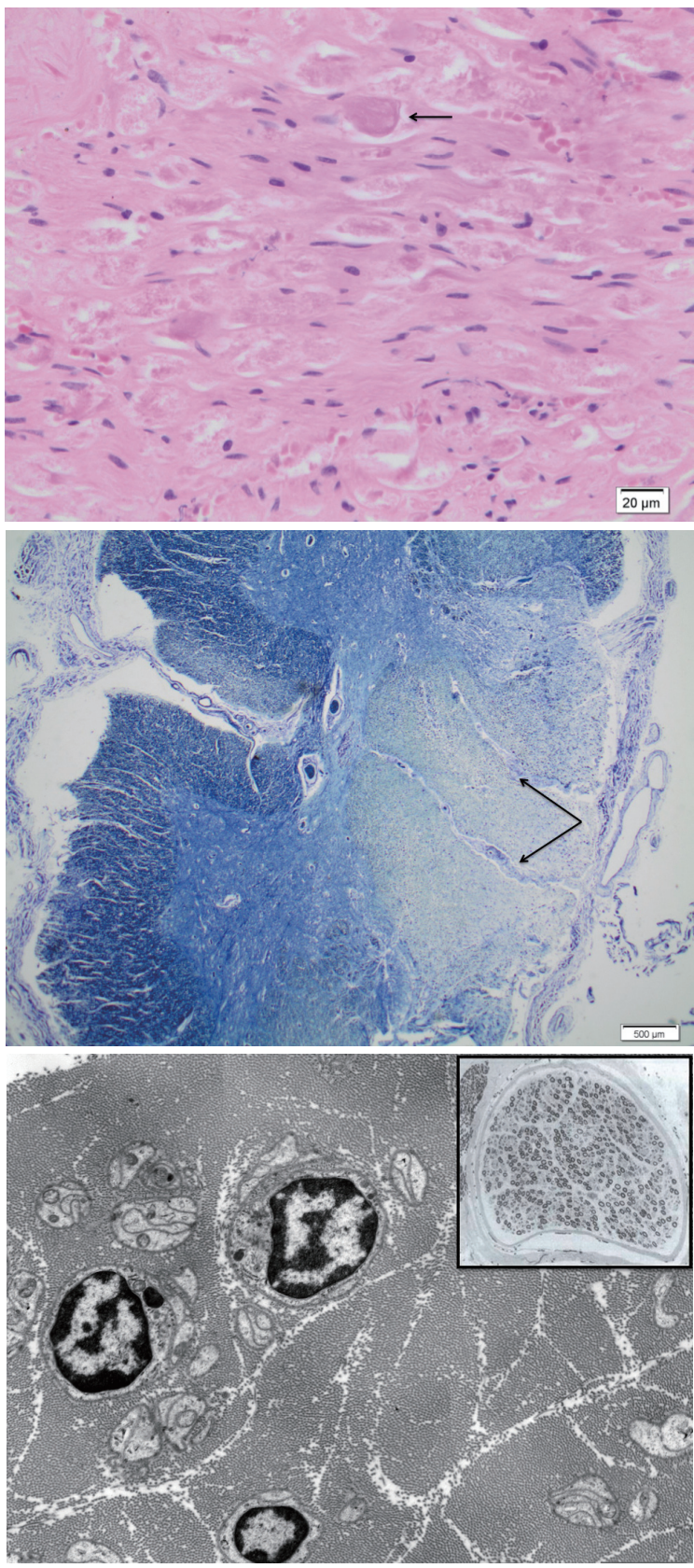

Fig. 7. Pathology underlying the somatosensory deficit seen in CANVAS. Upper panel: dorsal root ganglion showing severe loss of neurones (arrow); high power, H\&E; Middle panel: Cross-section of cervical spinal cord showing demyelination of the posterior columns (arrows) secondary to dorsal root ganglion neuronal loss; low power, Luxol fast blue; Lower panel: cross section sural nerve showed complete absence of axons with replacement fibrosis. No active wallerian degeneration or schwann cell proliferation was seen, electron microscopy; inset: normal sural nerve, electron microscopy. (Colours are visible in the online version of the article; http://dx.doi.org/10.3233/VES-140536) 


\section{References}

[1] R.W. Baloh, H.A. Jenkins, V. Honrubia et al., Visualvestibular interaction and cerebellar atrophy, Neurology 29 (1979), 116.

[2] K. Beerhorst, J. Tan, I.Y. Tan, P. Verschuure and A.P. Aldenkamp, Dual-energy X-ray absorptiometry versus quantitative ultrasonography in diagnosing osteoporosis in patients with refractory epilepsy and chronic antiepileptic drug use, Ther Adv Musculoskelet Dis 5(2) (2013), 59-6.

[3] E.T. Boereboom, J.A. Raymakers and S.A. Duursma, Mortality and causes of death after hip fractures in the Netherlands, Neth J Med 41 (1992), 4-10.

[4] A.M. Bronstein, S. Mossman and L.M. Luxon, The neckeye reflex in patients with reduced vestibular and optokinetic function, Brain 114 (1991), 1-11.

[5] K. Bürk, M. Fetter, M. Abele et al., Autosomal dominant cerebellar ataxia type I: oculomotor abnormalities in families with SCA1, SCA2, and SCA3, J Neurol 246(9) (1999), 789-797.

[6] N. Buttner, D. Geschwind, J.C. Jen, S. Perlman, S.M. Pulst and R.W. Baloh, Oculomotor phenotypes in autosomal dominant ataxias, Arch Neurol 55(10) (1998), 1353-1357.

[7] A.V. Chobanian, L. Volicer, C.P. Tifft, H. Gavras, C.S. Liang and D. Faxon, Mineralocorticoid-induced hypertension in patients with orthostatic hypotension, N Engl J Med 301 (1979), 68-73.

[8] M.C. Fahey, P.D. Cremer, S.T. Aw et al., Vestibular, saccadic and fixation abnormalities in genetically confirmed Friedreich ataxia, Brain 131(Pt 4) (2008), 1035-1045.

[9] F.M. Fouad-Tarazi, M. Okabe and H. Goren, Alpha sympathomimetic treatment of autonomic insufficiency with orthostatic hypotension, Am J Med 99 (1995), 604-610.

[10] R. Freeman, W. Wieling, F.B. Axelrod et al., Consensus statement on the definition of orthostatic hypotension, neurally mediated syncope and the postural tachycardia syndrome, Clin Auton Res 21(2) (2011), 69-72.

[11] J.M. Furman, S. Perlman and R.W. Baloh, Eye movements in Friedreich's ataxia, Arch Neurol 40(6) (1983), 343-346.

[12] C.R. Gordon, V. Joffe, G. Vainstein and N. Gadoth, Vestibuloocular arreflexia in families with spinocerebellar ataxia type 3 (Machado-Joseph disease), J Neurol Neurosurg Psychiatr 74(10) (2003), 1403-1406.

[13] S.J. Herdman, C.D. Hall, M.C. Schubert, V.E. Das and R.J. Tusa, Recovery of dynamic visual acuity in bilateral vestibular hypofunction, Arch Otolaryngol Head Neck Surg 133(4) (2007), 383-389.

[14] W. Ilg, Long-term effects of coordinative training in degenerative cerebellar disease. Movement Disorders: Official Journal of the Movement Disorder Society 25(13) (2010), 2239-2246.

[15] W. Ilg, M. Synofzik, D. Brotz, S. Burkard, M.A. Giese and L. Schols, Intensive coordinative training improves motor performance in degenerative cerebellar disease, Neurology 73(22) (2009), 1823-1830.

[16] J. Jankovic, J.L. Gilden, B.C. Hiner, H. Kaufmann, D.C. Brown, C.H. Coghlan and M. Rubin, Neurogenic orthostatic hypotension: A double-blind, placebo-controlled study with midodrine, Fouad-Tarazi FMAm J Med 95(1) (1993), 38-48.

[17] O. Johnell and J.A. Kanis, An estimate of the worldwide prevalence, mortality and disability associated with hip fracture, Osteoporosis International 15(11) (2004), 897-902.

[18] G.S. Keene, M.J. Parker and G.A. Pryor, Mortality and morbidity after hip fractures, BMJ 307 (1993), 1248-1250.

[19] D.E. Krebs, K.M. Gill-Body, P.O. Riley and S.W. Parker, Double-blind, placebo-controlled trial of rehabilitation for bi- lateral vestibular hypofunction: preliminary report, Otolaryngol Head Neck Surg 109(4) (1993), 735-741.

[20] T. Klockgether, L. Schols, M. Abele et al., Age related axonal neuropathy in spinocerebellar ataxia type 3/MachadoJoseph disease (SCA3/MJD), J Neurol Neurosurg Psychiatr 66(2) (1999), 222-224.

[21] A.H. Koeppen, A.N. Davis and J.A. Morral, The cerebellar component of Friedreich's ataxia, Acta Neuropathol 122(3) (2011), 323-330.

[22] A.H. Koeppen, Friedreich's ataxia: pathology, pathogenesis, and molecular genetics, J Neurol Sci 303(1-2) (2011), 1-12.

[23] D.E. Krebs, K.M. Gill-Body, P.O. Riley et al., Double-blind, placebo-controlled trial of rehabilitation for bilateral vestibular hypofunction: Preliminary report, Otolaryngol Head Neck Surg 109(4) (1993), 735-741.

[24] A.A. Leis, M. Kofler and M.A. Ross, The silent period in pure sensory neuronopathy, Muscle \& Nerve 15(12) (1992), 13451348.

[25] P. Lips, G. Evelien and N.M. van Schoor, Vitamin D supplements with or without calcium to prevent fractures. BoneKEy Reports 2014; Report 3, Article number: 512.

[26] P.A. Low, J.L. Gilden, R. Freeman, K.N. Sheng and M.A. McElligott, Efficacy of midodrine vs placebo in neurogenic orthostatic hypotension. A randomized, double-blind multicenter study. Midodrine Study Group, JAMA 277 (1997), 1046-1051.

[27] R. Marks, J.P. Allegrante, C. Ronald MacKenzie et al., Hip fractures among the elderly: causes, consequences and control, Ageing Research Reviews 2(1) (2003), 57-93.

[28] C.J. Mathias and J.R. Kimber, Treatment of postural hypotension, Journal of Neurology, Neurosurgery, and Psychiatry 65(3) (1998), 285-289.

[29] S. Maule, G. Papotti, D. Naso, C. Magnino, E. Testa and F. Veglio, Orthostatic hypotension: evaluation and treatment, Cardiovasc Hematol Disord Drug Targets 7 (2007), 63-70.

[30] A. Migliaccio, G. Halmagyi, L. Mcgarvie and P. Cremer, Cerebellar ataxia with bilateral vestibulopathy: description of a syndrome and its characteristic clinical sign, Brain: A Journal of Neurology 127(2) (2004), 280-293.

[31] J.L. Montastruc, I. Laborie, H. Bagheri and J.M. Senard, Drug-Induced Orthostatic Hypotension: A Five-Year Experience in a Regional Pharmacovigilance Centre in France, Clin Drug Invest 14(1) (1997), 61-65.

[32] National Institute for Health and Clinical Excellence (NICE). Neuropathic pain - pharmacological management: the pharmacological management of neuropathic pain in adults in non-specialist settings. Issued: November 2013. NICE clinical guideline 173 (accessed 03 April 2014).

[33] S.F. Noll, C.E. Bender and C.N. Marge, Rehabilitation of patients with swallowing disorders. In: Braddom RL, ed. Physical Medicine and Rehabilitation. Philadelphia, Pa: WB Saunders; 1996.

[34] N.J. Paik and T.R. Han, Critical review on the management for adult oropharyngeal dysphagia, Crit Rev Phys Rehabil Med 14 (2002), 247-272.

[35] M. Pandolfo, Friedreich ataxia: The clinical picture, J Neurol 256(1) (2009), 3-8.

[36] F. Porciuncula, C.C. Johnson and L.B. Glickman, The effect of vestibular rehabilitation on adults with bilateral vestibular hypofunction: A systematic review, J Vestib Res 22(5-6) (2012), 283-298.

[37] J. Richmond, G.B. Aharonoff, J.D. Zuckerman et al., Mortality after hip fracture, Journal of Orthopaedic Trauma 17(S Suppl) (2003), S2-5. 
[38] T. Rinne, A.M. Bronstein, P. Rudge et al., Bilateral loss of vestibular function: clinical findings in 53 patients, $J$ Neurol 245 (1998), 314-321.

[39] U. Rüb, L. Schöls, H. Paulson et al., Clinical features, neurogenetics and neuropathology of the polyglutamine spinocerebellar ataxias type 1, 2, 3, 6 and 7, Prog Neurobiol (2013), 38-66.

[40] L. Schöls, G. Amoiridis, T. Büttner, H. Przuntek, J.T. Epplen and O. Riess, Autosomal dominant cerebellar ataxia: phenotypic differences in genetically defined subtypes? Ann Neurol 42(6) (1997), 924-932.

[41] P.J. Spring, C. Kok, G.A. Nicholson, A.J. Ing, J.M. Spies, M.L. Bassett, J. Cameron, P. Kerlin, S. Bowler, R. Tuck and J.D. Pollard, Autosomal dominant hereditary sensory neuropathy with chronic cough and gastro-oesophageal reflux: clinical features in two families linked to chromosome 3p22p24, Brain 128(Pt 12) (2005), 2797-2810.

[42] M. Strupp, M. Dieterich and T. Brandt, The treatment and natural course of peripheral and central vertigo, Dtsch Arztebl Int 110(29-30) (2013), 505-506.

[43] D.J. Szmulewicz, S.N. Merchant and G.M. Halmagyi, Cerebellar ataxia with neuropathy and bilateral vestibular areflexia syndrome: A histopathologic case report, Otol Neurotol 32(8) (2011), e63-5.
[44] D.J. Szmulewicz, J.A. Waterston and G.M. Halmagyi, Sensory neuropathy as part of the cerebellar ataxia neuropathy vestibular areflexia syndrome, Neurology 76(22) (2011), 1903-1910.

[45] D.J. Szmulewicz, J.A. Waterston, H.G. MacDougall et al., Cerebellar ataxia, neuropathy, vestibular areflexia syndrome (CANVAS): A review of the clinical features and videooculographic diagnosis, Ann N Y Acad Sci 1233(1) (2011), 139-147.

[46] D.J. Szmulewicz, C.A. McLean, M.L. Rodriguez, A.M. Chancellor, S. Mossman, D. Lamont et al., Dorsal root ganglionopathy is responsible for the sensory impairment in CANVAS, Neurology 82(16) (2014), 1410-1415.

[47] H. Takegoshi and T. Murofushi, Vestibular evoked myogenic potentials in patients with spinocerebellar degeneration, SOTO 120(7) (2000), 821-824.

[48] C.J. Todd, C.J. Freeman, C. Camilleri-Ferrante, C.R. Palmer, A. Hyder, C.E. Laxton et al., Differences in mortality after fracture of hip: The East Anglian audit, BMJ 1995; 310: 904? Ther Adv Musculoskelet Dis 5(2) (2013), 59-66.

[49] J.A. Waterston, G.R. Barnes, M.A. Grealy and L.M. Luxon, Coordination of eye and head movements during smooth pursuit in patients with vestibular failure, J Neurol Neurosurg Psychiatry 55 (1992), 1125-1131. 